HEALTH PSYCHOLOGY REPORT · VOLUME 7(1), 2019 ORIGINAL ARTICLE
Inger Schou-Bredal $1 \mathrm{D}$

$1 \cdot \mathrm{A}, \mathrm{B}, \mathrm{C}, \mathrm{D}, \mathrm{E}, \mathrm{F}, \mathrm{G}$

Tore Bonsaksen

$2 \cdot \mathrm{B}, \mathrm{C}, \mathrm{D}, \mathrm{E}, \mathrm{F}$

Trond Heir

$3 \cdot \mathrm{A}, \mathrm{B}, \mathrm{C}, \mathrm{D}, \mathrm{E}, \mathrm{F}$

Laila Skogstad

$2 \cdot A, B, C, D, E, F$
Anners Lerdal

$4 \cdot \mathrm{A}, \mathrm{B}, \mathrm{C}, \mathrm{D}, \mathrm{E}, \mathrm{F}$

Tine Grimholt

$1 \cdot \mathrm{B}, \mathrm{C}, \mathrm{D}, \mathrm{E}, \mathrm{F}$

Øivind Ekeberg

$1 \cdot A, B, C, D, E, F$

\title{
Optimists report fewer physical and mental health conditions than pessimists in the general Norwegian population
}

\begin{abstract}
BACKGROUND
Several studies have found that optimism is associated with better health. However, all those studies have investigated the subject in a specific context: gender, age group, diagnosis, situation, or population segment. Given the association found between optimism and physical health, mental health and well-being in previous studies, one would expect optimistic individuals in the general population to report fewer physical and mental health conditions during their lifetimes than pessimists. The aim of the present study was to test this hypothesis.
\end{abstract}

\section{PARTICIPANTS AND PROCEDURE}

A random sample of 1792 people participated in a survey on a broad variety of mental and physical health conditions. In addition they filled out the Life Orientation TestRevised (LOT-R). Optimism was defined as a score of $\geq 17$ on the LOT-R.
RESULTS

Optimists reported a lower prevalence of a wide range of mental and physical health conditions compared with pessimists. The associations between optimism and better health conditions persisted for the majority of health conditions investigated, even after adjustment for age, gender and education. Overall, pessimists had a greater estimated risk of disease in general. In addition $11.30 \%$ of the pessimists reported having had five or more different diseases during their lifetimes, compared with $3.90 \%$ of the optimists.

\section{CONCLUSIONS}

Our results add to growing evidence that optimism plays an important role in health and support the view that fostering optimism is an appropriate strategy for promoting health.

\section{KEY WORDS}

survey; dispositional optimism; general population; health conditions

ORGANIZATION - 1: University of Oslo / Oslo University Hospital, Oslo, Norway · 2: Oslo and Akershus University College of Applied Science, Oslo, Norway · 3: University of Oslo, Norwegian Center for Violence and Traumatic Stress Studies, Oslo, Norway · 4: Lovisenberg Diakonale Hospital / University of Oslo, Oslo, Norway

authors' Contributions - A: Study design - B: Data collection · C: Statistical analysis - D: Data interpretation .

E: Manuscript preparation · F: Literature search · G: Funds collection

CORResponding AUthor - Inger Schou-Bredal, Ph.D., University of Oslo / Oslo University Hospital, Boks 1072 Blindern, Postboks 4950 Nydalen 0316, 0424 Oslo, Norway, e-mail: i.s.bredal@medisin.uio.no 


\section{BACKGROUND}

Optimism relates to the way people see the future; people who are optimists expect good things to happen to them across a variety of domains in their lives (Scheier \& Carver, 1985). A person is commonly referred to as being optimistic or pessimistic; however, a person may be more optimistic, more pessimistic or somewhere in the middle. Being an optimist does not mean denying or avoiding negative events. Optimism is defined as a personality trait, which means

Inger SchouBredal,

Tore Bonsaksen, Trond Heir, Laila Skogstad, Anners Lerdal, Tine Grimholt, Øivind Ekeberg it is relatively stable over time. A recent study found women's levels of optimism to be unchanged despite a diagnosis of breast cancer (Schou-Bredal \& Ekeberg, 2016). By contrast, it appears that for at least some people, the level of optimism may change over longer periods. In a previous study, one 10-year testretest correlation was only .35 (Segerstrom, 2007), while in another, it was .71 (Matthews, Raikkonen, Sutton-Tyrrell, \& Kuller, 2004). An estimate of the heritability of optimism is $25.00 \%$, which is substantial, although lower than that of many other personality traits (Plomin et al., 1992). Optimism has been found to be a universal phenomenon, and higher levels of optimism are associated with better subjective well-being and perceived physical health worldwide (Gallagher, Lopez, \& Pressman, 2013).

An individual personality is thought to develop early in life (Hampson \& Friedman, 2008), so it may influence health over the life course. Optimism is viewed as a trait that empowers people to cope with life's challenges, and it has been associated with a variety of adaptive outcomes (Carver, Scheier, \& Segerstrom, 2010). Studies on optimism and subjective well-being have mostly been conducted not only in medical settings, but also in the context of health crises. Research has shown that optimism actually helps people cope with stressful events in more beneficial ways (Allison, Guichard, \& Gilain, 2000; Schou, Ekeberg, Ruland, Sandvik, \& Karesen, 2004). Optimism appears to have a moderating role in the association between feelings of loss of hope and suicidal ideation (Hirsch \& Conner, 2006). Several studies have found that optimism is associated with better physical health (Cauley et al., 2017; Matthews et al., 2004; Segovia, Moore, Linnville, \& Hoyt, 2015; Tindle et al., 2017) and mental health (Brissette, Scheier, \& Carver, 2002; Schou et al., 2004; Segovia et al., 2015; Shnek, Irvine, Stewart, \& Abbey, 2001), although there are some exceptions (Gallagher et al., 2013). A recent study by Kim et al. (2017) found an association between lower levels of optimism and mortality due to heart disease, stroke, respiratory disease and cancer. Optimism has also been associated with healthy aging (Steptoe, Wright, Kunz-Ebrecht, \& Iliffe, 2006) and reduced risk of coronary heart disease (Boehm, Peterson, Kivimaki, \& Kubzansky, 2011; Kim, Smith, \& Kubzansky, 2014), and appears to be a protective factor against stroke (Kim, Park, \& Peter- son, 2011). Some studies have even found that optimists live longer than pessimists (Giltay, Geleijnse, Zitman, Hoekstra, \& Schouten, 2004; Tindle et al., 2009).

The most rigorous evidence for the association between optimism and better health comes from the cardiovascular domain. One would expect the prevalence of cardiovascular disease to be low in individuals with a high level of optimism (optimists) compared with that of individuals with low optimism (pessimists) in the general population. However, to our knowledge no study has investigated whether this is the case.

All of the above studies have investigated optimism in a specific context: gender, age group, diagnosis, situation, or population segment. Thus, the question remains whether optimism is related to broader health outcomes regardless of gender or age. The present study extends previous work by examining the relationship between optimism and subjective well-being, perceived health and a variety of medical conditions in a sample of the general population.

Given the association found between optimism and physical health, mental health and well-being in the abovementioned studies, one would expect optimistic individuals in the general population to report fewer physical and mental health conditions during their lifetimes than pessimists. The aim of the present study was to test this hypothesis.

\section{PARTICIPANTS AND PROCEDURE}

\section{STUDY DESIGN}

The Norwegian Population Study (NorPop) was a cross-sectional survey design study. The collected data reflect a wide variety of health conditions in the general population and provide national norm scores from several questionnaires used for assessing symptoms, attitudes and behaviors. For a detailed description of the survey methodology, see Schou-Bredal et al. (2017).

\section{PARTICIPANTS}

A random sample of adults ( $\geq 18$ years of age), stratified by age, gender and geographic region, was selected by the National Population Register for possible inclusion in the study. The questionnaires were sent by regular mail to 5500 people together with a letter explaining the purpose and procedures of the study. All data were collected in 2015 and 2016.

\section{DATA COLLECTION MEASUREMENTS}

The Life Orientation Test-Revised (LOT-R) was used to measure dispositional optimism (Scheier et al., 
1994). The LOT-R is composed of 10 self-reported items, where four items are "distractors" used to disguise the purpose of the measure. Of the remaining six items, three are phrased optimistically and three pessimistically. An example of an optimistic statement is "In uncertain times, I usually expect the best," whereas a pessimistic example is "If something can go wrong for me, it will." The respondents indicated the extent to which they agreed with each of the items on a five-point scale from 0 (strongly disagree) to 4 (strongly agree). For the present study, the total LOT-R score was calculated as the mean of the optimism and pessimism item scores, with the pessimism scores reversed. Thus, scores ranged from 0 to 4 , with higher scores indicating greater optimism.

Some researchers have split the LOT-R into two subscales: one consisting of the positive items and the other of the negative items. However, optimism is most accurately captured when the scale combines the positive items that are endorsed and the negative items that are rejected (Ryff \& Singer, 2007; Segerstrom, Evans, \& Eisenlogr-Moul, 2011). To date, no naturally occurring or clinically meaningful cutoff for distinguishing between optimists and pessimists has been established for the LOT-R. For theoretical reasons as well as those based on research in this area, we chose to use median splits (Iacobucci, Posavac, Kardes, Schneider, \& Popovich, 2015; Ryff \& Singer, 2007; Segerstrom et al., 2011). We dichotomized the LOT-R using the median of 17. Respondents were defined as pessimists if they scored $<17$ and optimists if they scored $\geq 17$.

\section{PERCEIVED QUALITY OF LIFE AND HEALTH}

The participants were asked to indicate on a scale from 0 (extremely poor) to 10 (excellent) how they would rate their perceived quality of life and health in the previous week.

\section{HEALTH CONDITIONS}

Health conditions were self-reported (yes vs. no) and included heart disease, stroke, respiratory disease, diabetes, cancer, osteoporosis, fibromyalgia, arthritis, arthrosis, prolonged muscle and skeletal disease, gastrointestinal disease, tinnitus, chronic pain, depression, anxiety, insomnia, eating disorder and psychosis. Body mass index (BMI) was calculated from self-reported weight and height. In addition, the participants were asked whether they had ever attempted to commit suicide or injured themselves on purpose.

\section{ETHICS}

Respondents gave their consent to participate in the research by returning their completed questionnaire in a sealed envelope. The Regional Committee for Medical and Health Research Ethics was consulted, and because the data were collected anonymously, no formal ethical approval was required.

\section{DATA ANALYSIS}

Data were analyzed using SPSS for Windows version 24 (IBM Corporation, 2016). Initial descriptive analyses employed frequencies, percentages, means and standard deviations (SDs) as appropriate. The LOT-R was dichotomized using the median score. A chi-square test was used to assess whether the frequency of health conditions differed significantly between optimists and pessimists. The risk estimates were calculated using a $2 \times 2$ table. Independent $t$ tests were used to compare optimists' and pessimists' quality of life and perceived health. Multivariate logistic regressions were conducted to assess the crosssectional association between optimism/pessimism and health conditions, controlling for age, gender and education. Multivariate linear multivariate regressions were conducted to assess the association between optimism/pessimism and perceived health and quality of life. The significance level in this study was set at $5.00 \%$.

\section{RESULTS}

A total of 1792 people (36.00\%) participated in the study. The mean age of the participants was 53.20 years $(S D=16.63$, age range $=18-94)$, and the majority were female $(53.10 \%)$. The respondents were evenly distributed with regard to place of residence. The mean LOT-R score for the whole population was $17.23(S D=3.05)$. The mean scores for pessimists and optimists were $14.27(S D=1.82)$ and $19.20(S D=19.18)$, respectively. Significantly $(p<.001)$ more optimists $(66.70 \%)$ than pessimists had received higher education $(41.60 \%)$ and significantly $(p<.001)$ more optimists $(67.00 \%)$ were employed (55.20\%) (Table 1).

The respondents rated their perceived health as a mean of $7.48(S D=2.30)$ on a scale from 0 to 10 , and their quality of life as $7.61(S D=2.19)$. Optimists' perceived health scores were significantly higher than those of pessimists: $8.11(S D=1.90)$ vs. $6.86(S D=2.38)$, respectively $(p<.001)$. Optimists also reported better quality of life than pessimists: 8.31 $(S D=1.80)$ vs. $6.86(S D=2.38)$, respectively $(p<.001)$.

The BMI of the respondents was $26.63(S D=18.87)$. The BMI of optimists was $25.97(S D=8.34)$ and 27.33 $(S D=13.14)$ for pessimists. There was significantly more obesity $\left(\mathrm{BMI}>30 \mathrm{~kg} / \mathrm{m}^{2}\right)$ among pessimists than among optimists (17.50\% vs. $12.50 \%, p=.012)$. The most prevalent health conditions reported in the
Optimists report fewer physical and mental health conditions than pessimists 
Table 1

Sociodemographic data

\begin{tabular}{lccc}
\hline & Optimist & Pessimist & $p$ \\
\hline Age in years; mean $(S D)$ & $51.65(15.76)$ & $54.65(17.60)$ & $<.001$ \\
Range (years) & $18-94$ & $18-93$ & n.s. \\
& $\%$ & $\%$ & n.s. \\
Gender & & & \\
Male & 46.10 & 47.60 & \\
Social status & & & \\
Married/cohabitant & 74.50 & 13.20 & \\
Single & 12.70 & 5.40 & \\
Divorced/separated & 5.50 & 5.70 &
\end{tabular}

Living companions

n.s.

Alone

17.30

21.80

Parents

3.10

4.90

Spouse/cohabitant

67.60

65.60

Other persons 18 years or older

5.00

3.70

Other persons under 18 years

7.00

4.10

Education

$<.001$

Primary school

4.70

10.90

Secondary school

18.10

36.10

High school

10.20

11.40

College or university less than 4 years

21.40

College or university 4 years or more

28.30

20.20

Employment

38.40

Employed

67.00

55.20

Full-time housewife/husband

0.50

0.60

Student

5.80

1.50

Unemployed/on leave

1.10

1.50

Retired

21.00

30.50

On social security/work assessment allowance

4.70

7.70

Military service

0.00

0.10

Residential area

Village (fewer than 2000 inhabitants)

18.80

$<.001$

Town (2000-19,999 inhabitants)

28.90

23.40

Small city $(20,000-99,999)$

23.30

26.00

Large city (100,000 or more inhabitants)

24.40

25.10

Note. Missing values ranged from $0.51 \%$ to $7.46 \%$ of the sociodemographic characteristics. 
general population were insomnia (36.90\%), depression $(28.90 \%)$ and chronic pain $(21.70 \%)$ (Table 2).

Secondary analyses were conducted controlling for age, gender and education. Except for heart disease, diabetes and respiratory disease, the health conditions presented in Table 2 continued to be associated with pessimism.

Secondary analyses were conducted for perceived health and quality of life controlling for age, gender and education. The association between optimism

Table 2

Lifetime prevalence of health problems reported by optimists and pessimists, and risk estimates for pessimists

\begin{tabular}{|c|c|c|c|c|c|c|}
\hline Health condition & $\begin{array}{c}\text { Total } \\
n=1792 \\
\%\end{array}$ & $\begin{array}{c}\text { Pessimist } \\
n=718 \\
\%\end{array}$ & $\begin{array}{c}\text { Optimist } \\
n=1074 \\
\%\end{array}$ & $p^{*}$ & $\begin{array}{c}\text { Risk } \\
\text { estimate }\end{array}$ & $95 \% \mathrm{Cl}$ \\
\hline Heart disease & 10.50 & 13.10 & 8.80 & .004 & 1.49 & $1.14-1.96$ \\
\hline Stroke & 2.80 & 4.50 & 1.70 & .001 & 2.65 & $1.50-4.70$ \\
\hline Respiratory disease & 11.80 & 13.80 & 10.50 & .037 & 1.13 & $1.10-1.70$ \\
\hline Diabetes mellitus & 5.20 & 6.40 & 3.90 & .020 & 1.31 & $0.90-1.90$ \\
\hline Cancer & 7.90 & 8.60 & 7.40 & .334 & 1.26 & $0.85-1.62$ \\
\hline Osteoporosis & 3.10 & 3.60 & 2.70 & .268 & 1.34 & $0.79-2.26$ \\
\hline Fibromyalgia & 4.50 & 7.20 & 2.60 & $<.001$ & 2.77 & $1.77-4.36$ \\
\hline Rheumatoid arthritis & 5.00 & 8.10 & 3.00 & $<.001$ & 2.71 & $1.78-4.13$ \\
\hline Arthrosis & 16.70 & 21.00 & 13.90 & $<.001$ & 1.51 & $1.23-1.86$ \\
\hline Prolonged muscle/skeletal disease & 13.10 & 15.70 & 11.40 & .008 & 1.38 & $1.09-1.76$ \\
\hline Gastrointestinal disease & 16.80 & 17.10 & 16.60 & .797 & 1.03 & $0.83-1.28$ \\
\hline Tinnitus & 17.80 & 22.40 & 14.70 & $<.001$ & 1.52 & $1.25-1.86$ \\
\hline Chronic pain & 21.70 & 28.40 & 17.10 & $<.001$ & 1.65 & $1.39-1.97$ \\
\hline Anxiety & 21.10 & 27.20 & 17.00 & $<.001$ & 1.59 & $1.33-1.91$ \\
\hline Depression & 28.90 & 35.70 & 24.40 & $<.001$ & 1.46 & $1.26-1.69$ \\
\hline Insomnia & 36.90 & 45.70 & 31.00 & $<.001$ & 1.47 & $1.31-1.66$ \\
\hline Eating disorder & 7.50 & 10.40 & 5.50 & $<.001$ & 1.90 & $1.37-2.64$ \\
\hline Psychosis & 1.80 & 3.30 & 0.80 & $<.001$ & 3.98 & $1.86-8.53$ \\
\hline Self-inflicted injury & 3.70 & 5.80 & 2.20 & $<.001$ & 2.61 & $1.60-4.28$ \\
\hline Attempted suicide & 3.00 & 4.50 & 2.00 & .004 & 2.17 & $1.28-3.71$ \\
\hline
\end{tabular}

Note. ${ }^{*} p$ values between pessimists' and optimists' perceived health - percentage scores.

Table 3

Total percentage count of mental and physical health conditions during one's lifetime

\begin{tabular}{|c|c|c|c|c|}
\hline Total number of health conditions & $\begin{array}{c}\text { Total } \\
n=1792\end{array}$ & $\begin{array}{c}\text { Pessimist } \\
n=718\end{array}$ & $\begin{array}{c}\text { Optimist } \\
n=1074\end{array}$ & $p^{*}$ \\
\hline 0 & 26.50 & 20.20 & 30.60 & \\
\hline 1 & 24.10 & 20.30 & 26.50 & \\
\hline 2 & 15.60 & 15.30 & 15.80 & \\
\hline 3 & 12.20 & 13.00 & 11.60 & \\
\hline 4 & 8.70 & 10.70 & 7.40 & \\
\hline 5 & 6.10 & 9.10 & 4.20 & \\
\hline$>5$ & 7.00 & 11.30 & 3.90 & $<.001$ \\
\hline
\end{tabular}

Note. ${ }^{*}$ Arthritis, arthrosis and prolonged muscle/skeletal disease were combined into one group and counted as one disease. 
Inger SchouBredal,

Tore Bonsaksen,

Trond Heir, Laila Skogstad, Anners Lerdal, Tine Grimholt, Øivind Ekeberg and better perceived health $(\beta=.19,95 \%$ confidence interval (CI) $0.65-1.09)$ and quality of life $(\beta=.26$, 95\% CI 0.97-1.39) remained significant $(p<.001)$.

Optimists reported a lower prevalence of insomnia (31.00\% vs. $45.70 \%)$, depression ( $24.00 \%$ vs. $35.70 \%)$ and chronic pain $(17.10 \%$ vs. $28.40 \%)$ compared with pessimists. The estimated risk of having one of these conditions for pessimists was 1.5-1.8 times that of optimists (Table 3).

We grouped arthritis, arthrosis and prolonged muscle/skeletal disease as "musculoskeletal system diseases," which were reported by $26.10 \%$ of the participants. Pessimists reported a significantly $(p<.001)$ higher prevalence of musculoskeletal system diseases $(31.80 \%)$ than optimists $(22.30 \%)$.

As shown in Table 2, we found that optimists reported a lower lifetime prevalence of the majority of physical and mental diseases. Moreover, the prevalence of suicide attempts and self-inflicted injuries was lower for optimists than for pessimists: $2.00 \%$ vs. $4.50 \%$ and $2.20 \%$ vs. $5.80 \%$, respectively. Overall, pessimists had a greater estimated risk of disease in general. In addition, $11.30 \%$ of the pessimists reported having had five or more different diseases during their lifetimes, compared with $3.90 \%$ of the optimists (Table 3)

\section{DISCUSSION}

In the present study, optimists reported a lower prevalence of a wide range of lifetime health conditions compared with pessimists. In addition, we found that optimists also had significantly fewer health conditions during their lifetime than pessimists. To our knowledge, this is the first study to show that pessimists report a higher prevalence of musculoskeletal diseases, tinnitus, insomnia, eating disorders, psychosis and self-inflicted injuries than optimists. In view of our findings, we wonder if optimism may be a protective factor against a broad range of diseases, not only strokes or cardiovascular disease, as reported by previous studies (Boehm et al., 2018; Kim et al., 2011). However, longitudinal studies are warranted before a conclusion can be drawn.

In this study, optimists reported higher levels of perceived health and quality of life; this is consistent with the majority of previous research findings that optimists report better subjective well-being (Gison, Dall'Armi, Donati, Rizza, \& Giaquinto, 2014; Kung et al., 2006; Pais-Ribeiro, da Silva, Meneses, \& Falco, 2007; Schou, Ekeberg, Sandvik, Hjermstad, \& Ruland, 2005) and perceived health (Gallagher et al., 2013; Rasmussen, Scheier, \& Greenhouse, 2009) than pessimists. The same applies to our findings that pessimists report a higher prevalence of anxiety and depression. Decades of research have demonstrated that greater optimism is associated with less distress in a wide range of groups and contexts, such as students starting college, survivors of missile attacks, cancer caregivers and cancer and cardiovascular patients (for an overview, see Carver et al., 2010). The present study found that optimists reported fewer suicide attempts than pessimists; this is consistent with previous findings associating optimism with fewer suicidal thoughts and behaviors (Bryan, Ray-Sannerud, Morrow, \& Etienne, 2013; Chang et al., 2013; Huffman et al., 2016; O'Keefe \& Wingate, 2013). However, to our knowledge, this is the first study to report that optimists report a lower prevalence of self-inflicted injuries. One reason that optimists report fewer suicide attempts or self-inflicted injuries may be that optimism is associated with better physiological adjustment to a stressful situation (Puig-Perez et al., 2015). Optimism is also associated with increased psychological well-being, fewer perceived stressors, a lower tendency to be depressed and problem-solving coping. Furthermore, optimism has been associated with higher scores in life satisfaction, positive effects, selfesteem, self-acceptance, positive relations with others, autonomy, environment mastery and personal growth (Bailey, Eng, Frisch, \& Snyder, 2007; Chang, 2009; Daukantaite \& Zukauskiene, 2012; Hart, Vella, \& Mohr, 2008; Vacek, Coyle, \& Vera, 2010). Optimism is also associated with the ability to find meaning after negative life events (Nolen-Hoecksema, 2000), and is not inevitably altered by changes in disease status (Schou, Ekeberg, Sandvik, \& Ruland, 2005).

The mechanism underlying the link between optimism and better health has become a topic of interest. It is possible that optimists enjoy better health because they lead healthier lifestyles and have better social networks. According to Carver and Scheier (2014), optimists appear more likely to take steps to protect their health, which may lead to healthier lifestyles. Indeed, evidence from a recent meta-analysis reported that optimists in both healthy and patient populations are less likely to smoke and more likely to eat healthier food and be physically active (Boehm et al., 2018). In the present study, we found that more optimists than pessimists had received higher education and fewer optimists than pessimists were obese. This is consistent with previous studies (Cauley et al., 2017; Salovey, Rothman, Detweiler, \& Steward, 2000; Smagula, Faulkner, Scheier, Tindle, \& Cauley, 2016; Steptoe et al., 2006). All these factors are associated with better health.

In summary, it appears that optimists take more direct action to safeguard their health by minimizing health risks. In addition, optimism has also been found to co-occur with higher socioeconomic status and social integration, which in turn may benefit mental and physical health (Kawachi \& Berkman, 2001; Lorant et al., 2003).

In addition to behavioral advantages, optimism may have biological benefits that improve health. It 
appears that optimism may have a direct positive effect on the neuroendocrine system and immune responses (Avvenuti, Baiardini, \& Giardini, 2016). Pessimism has been linked to higher ambulatory blood pressure and greater daily experience of stress (Raikkonen, Matthews, Flory, Owens, \& Gump, 1999). Pessimism has been linked to higher fasting insulin (Tindle et al., 2017), unhealthy lipid profiles (Boehm, Williams, Rimm, Ryff, \& Kubzansky, 2013) and inflammatory biomarkers (Roy et al., 2010). It has also been suggested that optimism is associated with reduced hypothalamus-pituitary-adrenal axis reactivity (Chida \& Hamer, 2008). Thus, optimism may induce an adaptive physiological adjustment that protects against stress-related disAnother mechanism underlying the link between optimism and better health is coping. A person's way of coping with a potential stressor could determine whether that stressor has an adverse effect (Cooper \& Payne, 1988). Optimists appear to experience less distress than pessimists in adversity. Studies have shown that optimists cope differently and more effectively than pessimists (Nes \& Segerstrom, 2006). Optimists generally appear to be approach copers, using problem-focused coping and seeking social support (Scheier \& Carver, 1985). Thus, they may be more compliant with their medical treatment regimens. This view is supported by findings that optimists show better adherence to treatment, both pharmacological and behavioral (Nabi et al., 2010; Tindle, Davis, \& Kuller, 2010). Furthermore, researchers have found that optimistic individuals have stronger feelings of self-worth and are more creative in their pursuit of goals than pessimists.

Because it appears that optimists engage in healthier behavior, future research should investigate whether improvements in optimism could translate to behavioral or health benefits. Optimism appears to be a promising target for intervention to enhance behavioral or health benefits. However, because optimism is considered a trait that is relatively stable over time, the question remains whether optimism is modifiable. Studies have found that some pessimists actually engage in goal-driven efforts to change the course of their negative expectations for the future, which in turn often lead to achieving goals (Norem \& Chang, 2002; Norem, 2008). Thus, the belief that one's future can be changed may induce some pessimists to act proactively in the pursuit of positive goals and outcomes (Chang, 2001). In terms of public health, several studies have found that optimism can be altered temporarily by interventions such as brief manipulations consisting of positive future thinking and positive imagery exercises (Peters, Flink, Boersma, \& Linton, 2010; Meevissen, Peters, \& Alberts, 2011; Murphy et al., 2015; Ji, Holmes, \& Blackwell, 2017); however, the durability of such alterations has not yet been examined.

\section{STRENGTHS AND LIMITATIONS}

Unlike previous investigations of optimism and health conditions, to our knowledge, this is the first study to investigate the prevalence of a wide range of both mental and physical health conditions in the general population, including both genders and adults ( $\geq 18$ years of age). The associations between optimism and better health conditions persisted for the majority of health conditions investigated, even after adjustment for age, gender and education.

Some limitations should be noted when interpreting the results of this study. Self-reported outcomes rely completely on the respondent as a source of information and are therefore subjective in nature. Optimists may be biased toward reporting better health than pessimists.

The analyses are based on cross-sectional survey data, which do not allow for conclusions regarding the direction of the relationship between optimism and health problems. Conversely, optimism appears to promote a healthier lifestyle, but poor health status may lead to more pessimism. An overall $36.00 \%$ response rate raises the question of whether the sample is representative of its target population. Declining response rates to mailed public health surveys have been reported in recent decades in several countries (Holbrook, Krosnick, \& Pfent, 2008). However, lower response rates do not necessarily produce more nonresponse errors (Holbrook et al., 2008). We consider our sample to be representative of the general Norwegian population (Schou-Bredal et al., 2017).

\section{CONCLUSIONS}

In the present study, optimism was broadly associated with fewer mental and physical health conditions in the general population. This finding adds to a growing body of evidence that optimism plays an important role in health and supports the notion that optimism is a promising target for intervention to enhance behavioral or health benefits.

\section{References}

Allison, P. J., Guichard, C., \& Gilain, L. (2000). A prospective investigation of dispositional optimism as a predictor of health-related quality of life in head and neck cancer patients. Quality of Life Research, 9, 951-960.

Avvenuti, G., Baiardini, I., \& Giardini, A. (2016). Optimism's explicative role for chronic diseases. Frontiers in Psychology, 7, 295. https://doi.org/10.3389/ fpsyg.2016.00295
Optimists report fewer physical and mental health conditions than pessimists 
Bailey, T. C., Eng, W., Frisch M. B., \& Snyder, C. R. (2007). Hope and optimism as related to life satisfaction. The Journal of Positive Psychology, 2, 168-175.

Boehm, J. K., Chen, Y., Koga, H., Mathur, M. B., Vie, L. L., \& Kubzansky, L. D. (2018). Is optimism associated with healthier cardiovascular-related behavior? Meta-analyses of 3 health behaviors. Circulation Research, 122, 1119-1134. https://doi. org/10.1161/circresaha.117.310828

Inger SchouBredal,

Tore Bonsaksen, Trond Heir, Laila Skogstad, Anners Lerdal, Tine Grimholt, Øivind Ekeberg

Boehm, J. K., Peterson, C., Kivimaki, M., \& Kubzansky, L. (2011). A prospective study of positive psychological well-being and coronary heart disease. Health Psychology, 30, 259-267. https://doi. org/10.1037/a0023124

Boehm, J. K., Williams, D. R., Rimm, E. B., Ryff, C., \& Kubzansky, L. D. (2013). Relation between optimism and lipids in midlife. American Journal of Cardiology, 111, 1425-1431. https://doi. org/10.1016/j.amjcard.2013.01.292

Brissette, I., Scheier, M. F., \& Carver, C. S. (2002). The role of optimism in social network development, coping, and psychological adjustment during a life transition. Journal of Personality and Social Psychology, 82, 102-111.

Bryan, C. J., Ray-Sannerud, B. N., Morrow, C. E., \& Etienne N. (2013). Optimism reduces suicidal ideation and weakens the effect of hopelessness among military personnel. Cognitive Therapy and Research, 37, 996-1003.

Carver, C. S., \& Scheier, M. F. (2014). Dispositional optimism. Trends in Cognitive Sciences, 18, 293-299.

Carver, C. S., Scheier, M. F., \& Segerstrom, S. C. (2010). Optimism. Clinical Psychology Review, 30, 879-889. https://doi.org/10.1016/j.cpr.2010.01.006

Cauley, J. A., Smagula, S. F., Hovey, K. M., Wactawski-Wende, J., Andrews, C. A., Crandall, C. J., LeBoff, M. S., Li, W., Coday, M., Sattari, M., \& Tindle, H. A. (2017). Optimism, cynical hostility, falls, and fractures: The Women's Health Initiative Observational Study (WHI-OS). Journal of Bone and Mineral Research, 32, 221-229. https://doi. org/10.1002/jbmr.2984

Chang, E. C. (2001). Cultural influences on optimism and pessimism: Differences in Western and Eastern construals of the self. In E. C. Chang (Ed.), Optimism and pessimism: Implication for theory, research, and practice (pp. 257-280). Washington DC: American Psychological Association.

Chang, E. (2009). An examination of optimism, pessimism, and performance perfectionism as predictors of positive psychological functioning in middle-aged adults: Does holding high standards of perfomance matter beyond generalized outcome expectancies? Cognitive Theraphy and Research, 33, 334-344.

Chang, E. C., Yu, E. A., Lee, J. Y., Hirsch, J. K., Kupfermann, Y., \& Kahle E. R. (2013). An examination of optimism/pessimism and suicide risk in pri- mary care patients: Does belief in a changeable future make a difference? Cognitive Therapy and Research, 37, 796-804.

Chida, Y., \& Hamer, M. (2008). Chronic psychological factors and acute physiological responses to laboratory-induced stress in healthy populations: a quantitative review of 30 years of investigation. Psychological Bulletin, 134, 829-885.

Cooper, C. L., \& Payne, R. (1988). Causes, coping and consequences of stress at work. England: Wiley, Chister.

Daukantaite D., \& Zukauskiene, R. (2012). Optimism and subjective well-being: Affectivity plays a secondary role in the relationship between optimism and global life satisfaction in the middle-aged women. Longitudinal and cross-cultural findings. Journal of Happiness Studies, 13, 1-16.

Gallagher, M. W., Lopez, S. J., \& Pressman, S. D. (2013). Optimism is universal: exploring the presence and benefits of optimism in a representative sample of the world. Journal of Personality, 81, 429-440. https://doi.org/10.1111/jopy. 12026

Giltay, E. J., Geleijnse, J. M., Zitman, F. G., Hoekstra, T., \& Schouten, E. G. (2004). Dispositional optimism and all-cause and cardiovascular mortality in a prospective cohort of elderly dutch men and women. Archives of General Psychiatry, 61, 1126-1135. https://doi.org/10.1001/archpsyc.61.11.1126

Gison, A., Dall'Armi, V., Donati, V., Rizza, F., \& Giaquinto, S. (2014). Dispositional optimism, depression, disability and quality of life in Parkinson's disease. Functional Neurology, 29, 113-119.

Hampson, S. E., \& Friedman, H. S. (2008). Personality and health: A lifespan perspective. In O. P. John, R. W. Robins, \& L. A. Pervin (Eds.), Handbook of personality: Theory and research (pp. 770-794). New York, NY: Guilford Press.

Hart, S. L., Vella, L., \& Mohr, D. C. (2008). Relationships among depressive symptoms, benefit-finding, optimism, and positive affect in multiple sclerosis patients after psychotherapy for depression. Health Psychology, 27, 230-238. https://doi. org/10.1037/0278-6133.27.2.230

Hirsch, J. K., \& Conner, K. R. (2006). Dispositional and explanatory style optimism as potential moderators of the relationship between hopelessness and suicidal ideation. Suicide and Life-Threatening Behavior, 36, 661-669. https://doi.org/10.1521/suli.2006.36.6.661

Holbrook, A. L., Krosnick, J. A., \& Pfent, A. (2008). The causes and consequences of response rates in surveys by the news media and government contractor survey research firms. In J. M. Lepkowski, C. Tucker, J. M. Brick, E. D. de Leeuw, L. Japec, P. J. Lavrakas, M. W. Link, \& R. L. Sangster (Eds.), Advances in Telephone Survey Methodology (pp. 499-528). New York: Wiley.

Huffman, J. C., Boehm, J. K., Beach, S. R., Beale, E. E., DuBois, C. M., \& Healy, B. C. (2016). Relationship 
of optimism and suicidal ideation in three groups of patients at varying levels of suicide risk. Jour nal of Psychiatric Research, 77, 76-84. https://doi. org/10.1016/j.jpsychires.2016.02.020

lacobucci, D., Posavac, S. S., Kardes, F. R., Schneider, M. J., \& Popovich, D. L. (2015). The median split. Robust, refined, and revived. Journal of Consumer Psychology, 25, 690-704.

IBM Corporation. (2016). SPSS for Windows, version 24. Armonk, NY: IBM Corp.

Ji, J. I., Holmes, E. A., \& Blackwell, S. E. (2017). Seeing light at the end of the tunnel: Positive prospective mental imagery and optimism in depression. Psychiatry Research, 247, 155-162.

Kawachi, I., \& Berkman, L. F. (2001). Social ties and mental health. Journal of Urban Health, 78, 458467. https://doi.org/10.1093/jurban/78.3.458

Kim, E. S., Hagan, K. A., Grodstein, F., DeMeo, D. L., De Vivo, I., \& Kubzansky, L. D. (2017). Optimism and Cause-Specific Mortality: A Prospective Cohort Study. American Journal of Epidemiology, 185, 21-29.

Kim, E. S., Park, N., \& Peterson, C. (2011). Dispositional optimism protects older adults from stroke: The health and retirement study. Stroke, 42, 2855-2859. https://doi.org/10.1161/strokeaha.111.613448

Kim, E. S., Smith, J., \& Kubzansky, L. D. (2014). Prospective study of the association between dispositional optimism and incident heart failure. Circulation: Heart Failure, 7, 394-400. https://doi. org/10.1161/circheartfailure.113.000644

Kung, S., Rummans, T. A., Colligan, R. C., Clark, M. M., Sloan, J. A., Novotny, P. J., \& Huntington, J. L. (2006). Association of optimism-pessimism with quality of life in patients with head and neck and thyroid cancers. Mayo Clinic Proceedings, 81, 1545-1552. https://doi.org/10.4065/81.12.1545

Lorant, V., Deliege, D., Eaton, W., Robert, A., Philippot, P., \& Ansseau, M. (2003). Socioeconomic inequalities in depression: a meta-analysis. American Journal of Epidemiology, 157, 98-112.

Matthews, K. A., Raikkonen, K., Sutton-Tyrrell, K., \& Kuller, L. H. (2004). Optimistic attitudes protect against progression of carotid atherosclerosis in healthy middle-aged women. Psychosomatic Medicine, 66, 640-644. https://doi.org/10.1097/01. psy.0000139999.99756.a5

Meevissen, Y. M., Peters, M. L., \& Alberts, H. J. (2011). Become more optimistic be imagining a best possible self: effect of a two week intervention. Journal of Behavior Therapy and Experimental Psychiatry, 3, 371-378.

Murphy, S. E., O’Donoghue, C., Drazich, E. H., Blacjwell, S. E., Nobre, C., \& Holmes, E. A. (2015). Imagining a brighetr future: the effect of positive imagery training on mood, prospective mental imagery and emotional bias in older adults. Psychiatry Research, 230, 36-43.
Nabi, H., Koskenvuo, M., Singh-Manoux, A., Korkeila, J., Suominen, S., Korkeila, K., \& Kivimaki, M. (2010). Low pessimism protects against stroke: The Health and Social Support (HeSSup) prospective cohort study. Stroke, 41, 187-190. https://doi. org/10.1161/STROKEAHA. 109.565440

Nes, L. S., \& Segerstrom, S. C. (2006). Dispositional optimism and coping: a meta-analytic review. Peronality and Social Psychology Review, 10, 235-251. https://doi.org/10.1207/s15327957pspr1003_3

Nolen-Hoecksema, S. (2000). Growth and resilience bereaved people. In J. Gillham (Ed.), The science of optimism and hope. (pp. 107-127). Philadelpia: Templeton Foundation.

Norem, J. K. (2008). Defensive pessimism as a positive self-critical tool. In E. C. Chang (Ed.), Self-criticism and self-ehancement: Theory, research, and clinical implication (pp. 89-104). Washington, DC: American Psychological Association.

Norem, J. L., \& Chang, E. C. (2002). The positive psychology of negative thinking. Journal of Clinical Psychology, 58, 993-1001.

O'Keefe, V. M., \& Wingate, L. R. (2013). The role of hope and optimism in suicide risk for American Indians/Alaska Natives. Suicide and Life-Threatening Behavior, 43, 621-633. https://doi.org/10.1111/ sltb. 12044

Pais-Ribeiro, J., da Silva, A. M., Meneses, R. F., \& Falco, C. (2007). Relationship between optimism, disease variables, and health perception and quality of life in individuals with epilepsy. Epilepsy and Behavior, 11, 33-38. https://doi.org/10.1016/j.yebeh.2007.04.010

Peters, M. L, Flink, I. K, Boersma, K., \& Linton, S. J. (2010). Manipulating optimism: can imagining a best possible self be used to increased positive future expectancies? Journal of Positive Psychology, 5, 204-211.

Plomin, R., Scheier, M. F., Bergeman, C. S., Pedersen, N. L., Nesselroade, J. R., \& McClearn, G. E. (1992). Optimism, pessimism, and mental health: A twin/adoption analysis. Personality and Individual Differences, 13, 921-930.

Puig-Perez, S., Villada, C., Pulopulos, M. M., Almela, M., Hidalgo, V., \& Salvador, A. (2015). Optimism and pessimism are related to different components of the stress response in healthy older people. International Journal of Psychophysiology, 98, 213221. https://doi.org/10.1016/j.ijpsycho.2015.09.002

Raikkonen, K., Matthews, K. A., Flory, J. D., Owens, J. F., \& Gump, B. B. (1999). Effects of optimism, pessimism, and trait anxiety on ambulatory blood pressure and mood during everyday life. Journal of Personality and Social Psychology, 76, 104-113.

Rasmussen, H. N., Scheier, M. F., \& Greenhouse, J. B. (2009). Optimism and physical health: A metaanalytic review. Annals of Behavioral Medicine,
Optimists report fewer physical and mental health conditions than pessimists 
Inger SchouBredal,

Tore Bonsaksen,

Trond Heir, Laila Skogstad, Anners Lerdal, Tine Grimholt, Øivind Ekeberg
37, 239-256. https://doi.org/10.1007/s12160-0099111-x

Roy, B., Diez-Roux, A. V., Seeman, T., Ranjit, N., Shea, S., \& Cushman, M. (2010). Association of optimism and pessimism with inflammation and hemostasis in the Multi-Ethnic Study of Atherosclerosis (MESA). Psychosomatic Medicine, 72, 134-140. https://doi. org/10.1097/PSY.0b013e3181cb981b

Ryff, C. D., \& Singer, B. (2007). What to do about positive and negative items in studies of psychological well-being and ill-being? Psychotherapy and Psychosomatics, 76, 126-129.

Salovey, P., Rothman, A. J., Detweiler, J. B., \& Steward, W. T. (2000). Emotional states and physical health. American Psychologist, 55, 110-121.

Scheier, M. F., \& Carver, C. S. (1985). Optimism, coping, and health: assessment and implications of generalized outcome expectancies. Health Psychology, 4, 219-247.

Scheier, M. F., Carver, C. S., \& Bridges, M. W. (1994). Distinguishing optimism from neuroticism (and trait anxiety, self-mastery and self-esteem), a reevaluation of the Life Orientation Test. Journal of Personality and Social Psychology, 67, 1063-1078.

Schou-Bredal, I., \& Ekeberg, Ø. (2016). The stability of dispositional optimism in relation to receiving or not receiving a cancer diagnosis. Psychology, 7, 806-814.

Schou-Bredal, I., Heir, T., Skogstad, L., Bonsaksen, T., Lerdal, A., Grimholt, T., \& Ekeberg, Ø. (2017). Population-based norms of the Life Orientation TestRevised (LOT-R). International Journal of Clinical and Health Psychology, 17, 216-224. https://doi. org/https://doi.org/10.1016/j.ijchp.2017.07.005

Schou, I., Ekeberg, Ø., Ruland, C. M., Sandvik, L., \& Karesen, R. (2004). Pessimism as a predictor of emotional morbidity one year following breast cancer surgery. Psychooncology, 13, 309-320. https://doi.org/10.1002/pon.747

Schou, I., Ekeberg, Ø., Sandvik, L., Hjermstad, M. J., \& Ruland, C. M. (2005). Multiple predictors of health-related quality of life in early stage breast cancer. Data from a year follow-up study compared with the general population. Quality of Life Research, 14, 1813-1823. https://doi.org/10.1007/ s11136-005-4344-z

Schou, I., Ekeberg, Ø., Sandvik, L., \& Ruland, C. M. (2005). Stability in optimism-pessimism in relation to bad news: a study of women with breast cancer. Journal of Personality Assessment, 84, 148154. https://doi.org/10.1207/s15327752jpa8402_04

Segerstrom, S. C. (2007). Optimism and resources: Effects on each other and on health over 10 years. Journal of Research Personality, 41, 772-786. https:// doi.org/10.1016/j.jrp.2006.09.004

Segerstrom, S. C., Evans, D. R., \& Eisenlogr-Moul, T. A. (2011). Optimism and pessimism dimensjons in the
Life Orientation Test-Revised: method and meaning. Journal of Research Personality, 45, 126-129.

Segovia, F., Moore, J. L., Linnville, S. E., \& Hoyt, R. E. (2015). Optimism predicts positive health in repatriated prisoners of war. Psychological Trauma, 7, 222-228. https://doi.org/10.1037/a0037902

Shnek, Z. M., Irvine, J., Stewart, D., \& Abbey, S. (2001). Psychological factors and depressive symptoms in ischemic heart disease. Health Psychology, 20, 141-145.

Smagula, S. F., Faulkner, K., Scheier, M. F., Tindle, H. A., \& Cauley, J. A. (2016). Testing the independence of multiple personality factors in relation to health among community-dwelling older men. Journal of Aging Health, 28, 571-586. https:// doi.org/10.1177/0898264315597649

Steptoe, A., Wright, C., Kunz-Ebrecht, S. R., \& Iliffe, S. (2006). Dispositional optimism and health behaviour in community-dwelling older people: associations with healthy ageing. Britsh Journal of Health Psychology, 11, 71-84. https://doi. org/10.1348/135910705x42850

Tindle, H. A., Davis, E., \& Kuller, L. (2010). Attitudes and cardiovascular disease. Maturitas, 67, 108-113. https://doi.org/10.1016/j.maturitas.2010.04.020

Tindle, H. A., Chang, Y. F., Kuller, L. H., Manson, J. E., Robinson, J. G., Rosal, M. C., \& Matthews, K. A. (2009). Optimism, cynical hostility, and incident coronary heart disease and mortality in the Women's Health Initiative. Circulation, 120, 656-662. https://doi.org/10.1161/circulationaha. 108.827642

Tindle, H. A., Duncan, M. S., Liu, S., Kuller, L. H., Fugate Woods, N., Rapp, S. R., Kroenke, C. H, Coday, M., Loucks, E. B., Lamonte, M. J., Progovac, A. M., Salmoirago-Blotcher, E., Walitt, B. T., Yuo, N. Y., \& Freiberg, M. S. (2017). Optimism, pessimism, cynical hostility, and biomarkers of metabolic function in the Women's Health Initiative. Journal of Diabetes, 10, 512-523. https://doi. org/10.1111/1753-0407.12584

Vacek, K. R., Coyle L. D., \& Vera E. M. (2010). Stress, self-esteem, hope, optimism and well-being in urban ethnic minority adolescents. Journal of Multicultural Counseling and Development, 38, 99-111. 